\title{
Upper Eyelid Necrosis Secondary to Hordeolum: A Case Report
}

\author{
Júlia D. Rossetto ${ }^{a, b} \quad$ Eliana A. Forno ${ }^{c}$ Melina Correia Morales ${ }^{a, d}, e, f$ \\ Julio Cesar Moreira ${ }^{e} f$ Pedro V. Ferraria, $d, e, f$ Bruno T. Herrerias $a, d, e, f$ \\ Flavio E. Hirai ${ }^{a}, d, e, f \quad$ Carolina P.B. Gracitelli ${ }^{a}, d, e, f$ \\ aDepartment of Ophthalmology, Federal University of São Paulo, São Paulo, Brazil; \\ ${ }^{b}$ Department of Pediatric Ophthalmology, Institute of Childcare and Pediatrics Martagão \\ Gesteira-Federal University of Rio de Janeiro (IPPMG-UFRJ), Rio de Janeiro, Brazil; \\ 'Universidade de São Paulo, São Paulo, Brazil; ${ }^{\mathrm{C} C}$ Centro de Estudos Alcides Hirai, Ver Mais \\ Oftalmologia, São Paulo, Brazil; eVera Cruz Oftalmologia, Campinas, Brazil; ' F'Fundação \\ Roberto Rocha Brito, Hospital Vera Cruz, Campinas, Brazil
}

\section{Keywords}

Hordeolum · Eyelid diseases · Necrotizing fasciitis · Necrosis

\begin{abstract}
We reported a case of upper eyelid necrosis initially misdiagnosed as a preseptal cellulitis following a hordeolum externum resulting in great damage to the upper eyelid (anterior lamella). The infection was successfully treated with surgical cleansing, drainage, and endovenous antibiotics. Early treatment may avoid severe complications such as eyelid deformity, systemic involvement, and blindness.
\end{abstract}

\section{Introduction}

Hordeolum is a relatively common disease that can lead to painful inflammation of the eyelid margin, and it is usually caused by bacterial infection. Incidence rates for hordeolum are not available because most cases are not reported. Hordeolum tends to occur in younger people but is not limited to any age, gender, or racial groups [1-3]. In most of the cases, the inflamed lesion drains spontaneously and resolves with topical antibiotic and local warm compresses [2, 4-7]. However, if unresolved, acute internal hordeolum can lead to cellulitis and abscess.

Orbital cellulitis is an infection of the soft tissues characterized by the patient's report of eye pain, associated with local edema and fever. The orbital septum divides the preseptal and orbital spaces [8]. Usually, local skin trauma allows infection of the preseptal tissues, whereas 
Fig. 1. Patient showing NF with eschar formation in upper eyelid in the right eye at the day of admission at the hospital. NF, necrotizing fasciitis.

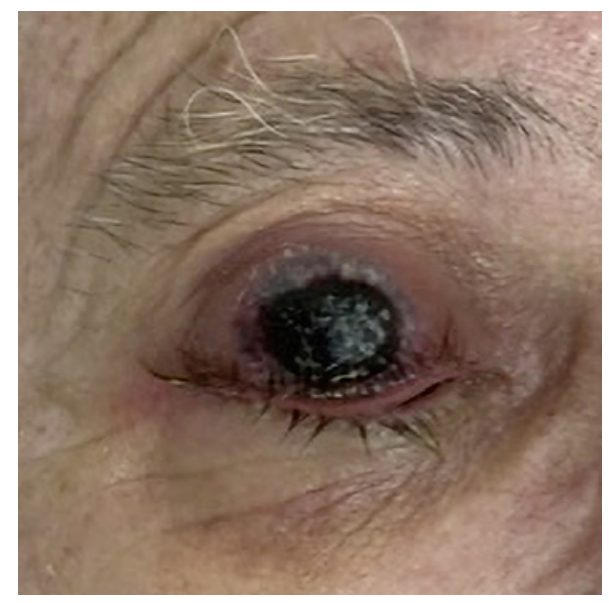

extravasation of a sinus infection can be associated with orbital infections [9-12]. The most common etiologies of these infections are Staphylococcus, Streptococcus, or/and Haemophilus $[8,13]$. Orbital tomography with intravenous contrast media distinguishes preseptal from orbital cellulitis and can identify abscess formation [14]. If abscess is present and not drained, cutaneous complications such as ptosis, lid scarring, and necrosis may occur. We describe a case of upper eyelid necrosis initially misdiagnosed as a preseptal cellulitis following a hordeolum externum (stye) compromising the upper eyelid.

\section{Case Report}

A Caucasian 68-year-old male, without systemic diseases, was admitted in March 2020 to a tertiary care center (Hospital Vera Cruz, Campinas, São Paulo, Brazil) with history of right upper eyelid swelling and redness for 10 days, which became progressively worse. He denied fever, worsening of visual acuity, or pain due to eye movements.

At presentation, the patient's right eye was closed by erythematous and swelling of the right upper lid (Fig. 1). Vital signs at the time of hospital admission were as follows: systemic blood pressure $=130 \times 70 \mathrm{~mm} \mathrm{Hg}$, cardiac frequency $=71 \mathrm{bpm}$, and body temperature $=$ $37.1^{\circ} \mathrm{C}$. The full blood count presented a white blood count of leukocytes $=6,478 \mathrm{~mm}^{3}$ (neutrophils $=4,060 \mathrm{~mm}^{3}$, eosinophils $30 \mathrm{~mm}^{3}$, basophils $=20 \mathrm{~mm}^{3}$, lymphocytes $=1,790$ $\mathrm{mm}^{3}$, and monocytes $=580 \mathrm{~mm}^{3}$ ). All of them were within the normal range.

Ophthalmologic exam at the time of admission showed visual acuity of $0.4 \log$ MAR in both eyes (OU) with spectacles, clear conjunctiva, clear cornea, and nuclear cataract $2+$ in $\mathrm{OU}$. Ocular motility and pupillary reflex were normal in OU. The intraocular pressure was $12 \mathrm{~mm}$ $\mathrm{Hg}$ in OU (with Icare tonometer, which is a rebound tonometer). Fundoscopy showed pink optic disc with sharp margins and a cup to disc ratio of 0.5 in OU.

Computerized tomography revealed preseptal and soft tissue edema with an abscess in the anterior right upper eyelid but no signs of orbital involvement or orbital fractures. Figure 2 presents the aspect of both eyelids in the tomography. A presumptive diagnosis of hordeolum with preseptal cellulitis and abscess was made, and intravenous amoxicillin and clavulanate potassium 500/125 mg were administrated twice a day.

The development of purulent discharge from the upper eyelid with an abscess and necrosis was evident. Therefore, the patient underwent abscess drainage and wound debridement. During the procedure, necrosis was observed involving almost the full thickness of the right upper eyelid, measuring $30 \times 30 \mathrm{~mm}$ in the central area. The tissue surrounding

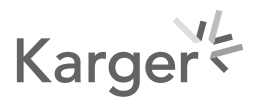


Fig. 2. Tomography presenting preseptal edema and heterogeneous fluid, suggesting abscess in the right eyelid.
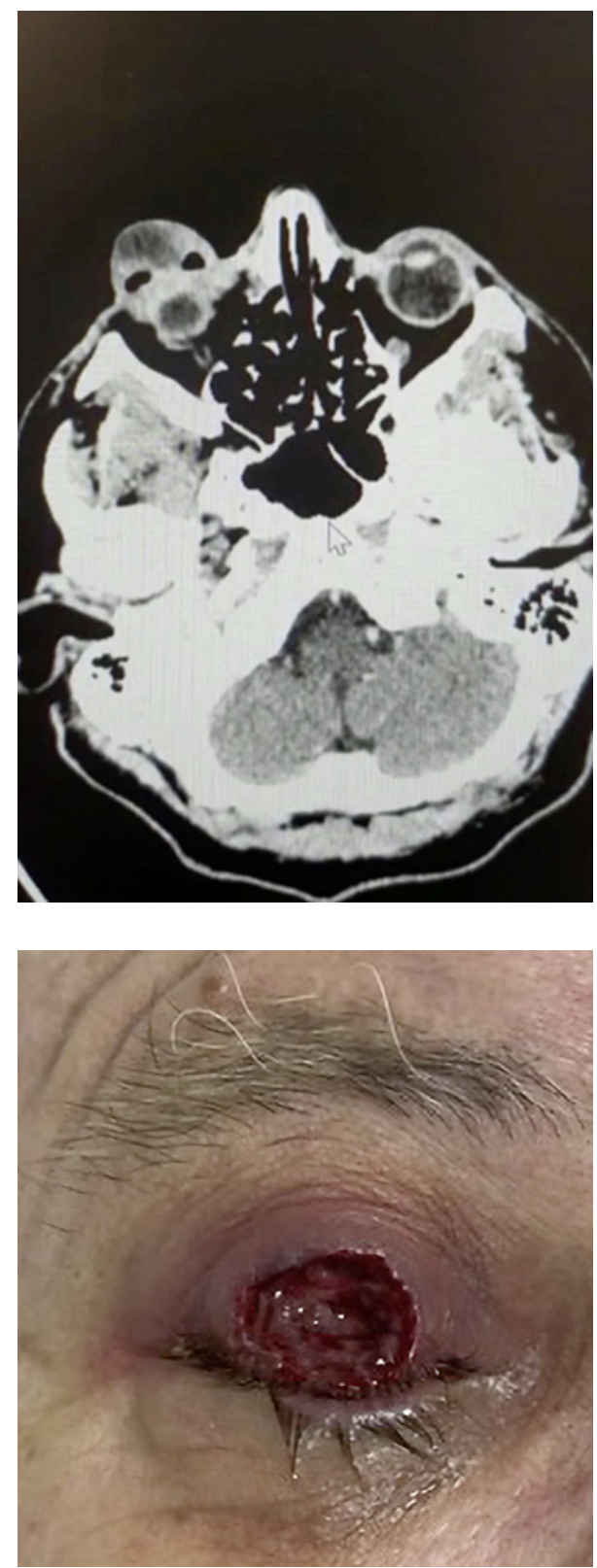

Fig. 3. Patient presenting the upper eyelid aspect of the right eye minutes after the debridement.

the abscess was friable and necrotic and did not bleed. The necrotic tissue was debrided until healthy viable tissue appeared throughout the wound and no evidence of infection was present in the reminiscent tissue. The wound was left open to heal by secondary intension. Figure 3 presents the eyelid aspect immediately after the surgery.

Given the clinical improvement in his local and systemic condition, the patient was continued on intravenous amoxicillin and clavulanate twice a day for $48 \mathrm{~h}$ and was discharged with the same oral antibiotics. He also started using topical medication with retinol acetate $(10,000 \mathrm{IU} / \mathrm{g})$, amino acids $(25 \mathrm{mg} / \mathrm{g})$, methionine $(5 \mathrm{mg} / \mathrm{g})$, and chloramphenicol $(5 \mathrm{mg} / \mathrm{g})$ in the affected eyelid for 7 days, 3 times a day.

Seven days after debridement, he presented satisfactory cicatrization without any symptoms (Fig. 4). After 2 months, the eyelid was completely healed with no retraction (Fig. 5a, b). 
Fig. 4. Upper eyelid aspect after 15 days of the debridement.
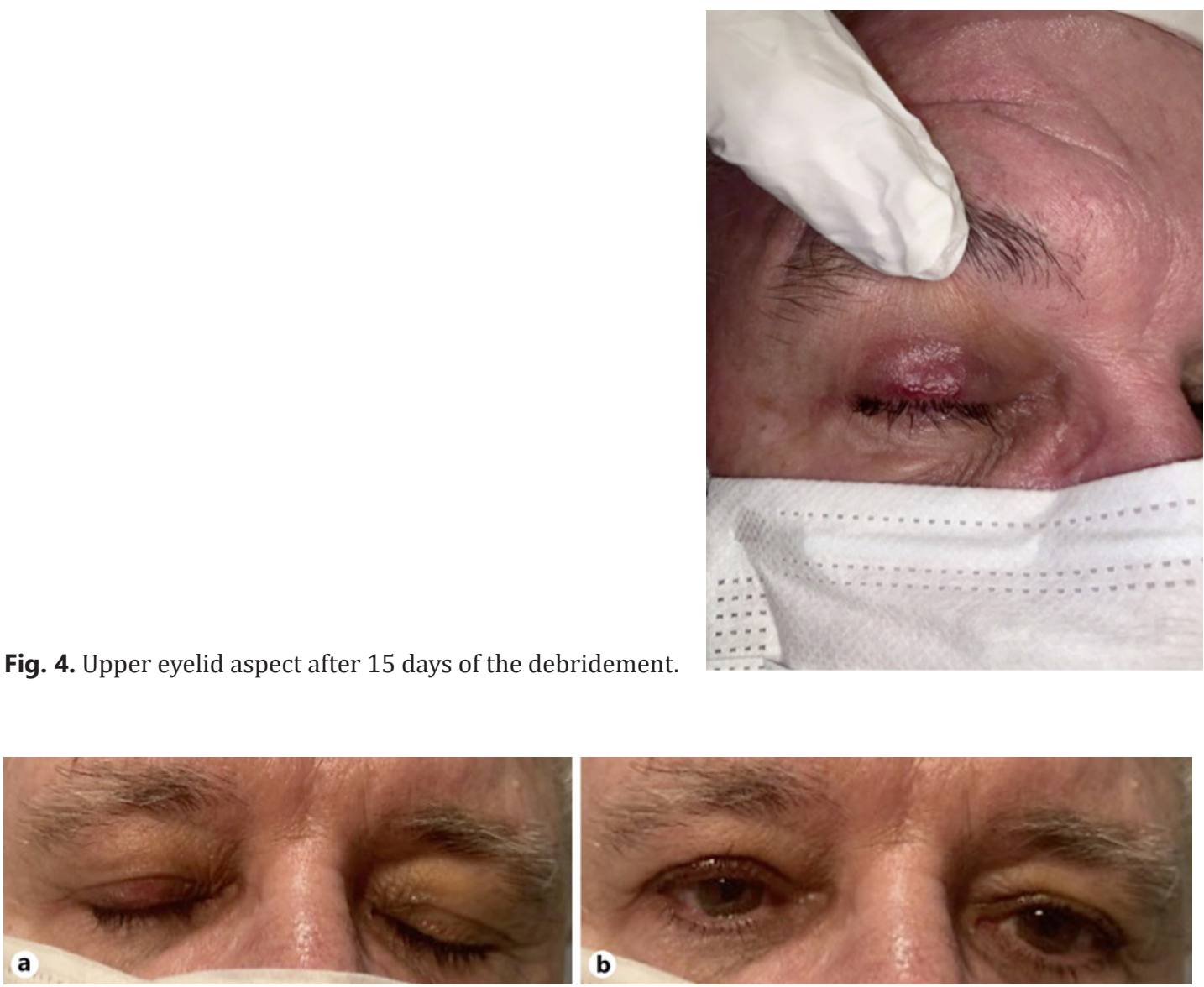

Fig. 5. Upper eyelid aspect after 2 months of debridement with closed (a) and opened (b) eyes.

\section{Discussion}

The present study describes a case of an untreated hordeolum that became a preseptal cellulitis with an abscess. Shortly, the abscess progressed to extensive eyelid necrosis. This case highlights the need for close monitoring and performing early intervention in some cases of hordeolum that do not show a benign course and can lead to extensive involvement of the eyelid, compromising its anatomy and ultimately the patient's health.

Hordeolum is one of the most common diseases of the eye adnexa. Patients with different ages can be affected, and the onset is either spontaneous or associated with risk factors such as lid hygiene, blepharitis, or systemic disease $[1-3,7,15]$. The size of swelling might be a direct indicator of the severity of the infection [6], and recurrence is usually associated with underlying causes including blepharitis, acne rosacea, trichiasis, and cicatricial ectropion [16].

Most cases of hordeolum have a spontaneous resolution, not demanding professional medical treatment [17]. Home therapies, including heated compresses, lid scrubs, and overthe-counter medications are often employed without medical consultation [18]. Initial treatment of hordeolum is indeed conservative, typically limited to application of warm compresses several times a day and topical antibiotics $[2,4-7,19]$. If the condition is severe and resistant to topical antibiotics, systemic antibiotics or surgical incision and drainage may be implemented [16]. However, when an abscess is diagnosed, its drainage is mandatory. 
Usually, the eyelids tend to be resistant to infections because of their rich vascular supply; however, there is a susceptibility to necrosis due to the underlying anatomy [20,21]. The tenuous attachment of the thin skin and the lack of subdermal adipose tissue favors the accumulation of inflammatory edema secondary to an infection. This results in impaired capillary blood flow leading to skin necrosis [22, 23]. Major morbidity of eyelid necrosis includes loss of skin and soft tissue leading to cosmetic disfigurement and functional problems [24].

In the present study, our patient reported symptoms of hordeolum one week before. The delay in seeking assistance occurred due to the COVID-19 quarantine and permitted the progression to preseptal cellulite with an abscess. As the disease rapidly worsened to eyelid necrosis, intravenous antibiotics were started to avoid dissemination since the main differential diagnosis is necrotizing fasciitis (NF), an entity that can be fatal.

$\mathrm{NF}$ is a rare, rapidly progressing bacterial infection that originates in the fascia and involves muscles and subcutaneous fat with later necrosis of the overlying skin [25-28]. Periorbital NF is more commonly a type $2 \mathrm{NF}$ (monomicrobial) $[26,29]$ in otherwise healthy, immunocompetent people; is bilateral in $35 \%$ of all cases; most frequently comes from the extension of an infected wound or breach in skin tissues; and in $28 \%$ of all cases, no triggering incident is found [30,31]. Fortunately, the prompt treatment prevented our patient from developing fascial or systemic involvement.

Other complications after a hordeolum (besides NF) may also happen. Early recognition of clinical signs of local eyelid complications of hordeolum is fundamental. It includes tenderness to palpation, erythema, swelling, and warm skin [32]; later, blisters, followed by crepitation, skin anesthesia, and skin necrosis [32]. Clinical clues are pain out of proportion to the physical findings, failure to respond to broad-spectrum antibiotics, skin bullae, and soft tissue gas on X-ray [25]; also, severe leukocytosis and an elevated C-reactive protein [33]. Computerized tomography is the imaging modality of choice because it identifies the extent of the infection, the presence of fluid-filled bullae and gas, and can guide the surgical exploration [34].

Appropriate recognition, prompt surgical debridement, and empirical broad-spectrum antibiotic therapy are critical for the management of eyelid necrosis [35, 36]. Early diagnosis of NF is frequently challenging as the initial clinical signs and symptoms may be similar to severe cellulitis. Therefore, a high index of suspicion is necessary, especially in systemically unwell patient or unresponsive to standard antimicrobial therapy, with rapidly progressing skin changes [36]. Surgical debridement allows better penetration of the antibiotics and limits bacterial load but should be limited to avoid exposure of the tarsus and levator aponeurosis. Operative findings include grayish necrotic fascia, lack of resistance of superficial fascia to blunt dissection, lack of bleeding of fascia during dissection, and foul-smelling pus [28]. Scarring of the intraorbital fascia may influence eyelid lengthening and may compromise eyelid and eyebrow motility $[37,38]$. Ectropion, exposure keratitis, and contracture are complications associated with secondary intention healing and can require reconstructive procedures such as split- or full-thickness skin grafts or Z-plasties [20, 22, 23, 39, 40].

Indeed, our patient presented no signs of systemic infection at the moment of admission (fever, leukocytosis, and elevated C-reactive protein); however, because of the characteristics of early skin necrosis, the general practitioner started intravenous antibiotics and asked for an ophthalmological evaluation. Favorably, after debridement, our patient did not progress to severe complications such as systemic infection, intraorbital involvement, eyelid contracture, exposure keratitis, or blindness.

In conclusion, hordeolum complications that lead to skin necrosis or NF are rare and difficult to diagnose. A warning sign in our case was early extensive skin necrosis, which is usually found in later stages. We reported an eyelid necrosis case that started promptly after a hordeolum. General physicians or general ophthalmologists should be aware and concerned

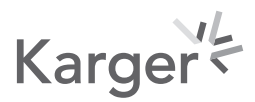


about hordeolum complications as early and aggressive management holds the key to limiting the morbidity, systemic infections, and ultimately, mortality associated with these conditions.

\section{Acknowledgement}

To Fundação Roberto Rocha Brito, Hospital Vera Cruz.

\section{Statement of Ethics}

Written informed consent was obtained from the patient for publication of this case report.

\section{Conflict of Interest Statement}

The authors have no conflicts of interest to declare.

\section{Funding Sources}

To Fundação Roberto Rocha Brito, Hospital Vera Cruz, for financial support.

\section{Author Contributions}

Conceived and designed the experiments: J.R., E.A.F., M.C.M., J.C.P.M., and P.V.F. Performed the experiments: J.R., E.A.F., M.C.M., J.C.P.M., P.V.F., B.T.H., F.E.H., and C.P.B.G. Analyzed the data: J.R., E.A.F., M.C.M., J.C.P.M., P.V.F., B.T.H., F.E.H., and C.P.B.G. Contributed reagents/materials/ analysis tools: J.R., E.A.F., M.C.M., J.C.P.M., and P.V.F. Contributed to the writing of the manuscript: J.R., E.A.F., M.C.M., J.C.P.M., P.V.F., B.T.H., F.E.H., and C.P.B.G.

\section{References}

1 Fuchs E. Textbook of ophthalmology. Philadelphia, PA: JB Lippincott Company; 1911.

2 Lederman C, Miller M. Hordeola and chalazia. Pediatr Rev. 1999;20(8):283-4.

3 Roodyn L. Staphylococcal infections in general practice. Br Med J. 1954;2(4900):1322-5.

4 Black RL, Terry JE. Treatment of chalazia with intralesional triamcinolone injection. J Am Optom Assoc. 1990; 61(12):904-6. PubMed PMID: 2081834

5 Diegel JT. Eyelid problems. Blepharitis, hordeola, and chalazia. Postgrad Med. 1986;80(2):271-2.

6 Lebensohn JE. Treatment of hordeola. Postgrad Med. 1950;7(2):133.

7 Wald ER. Periorbital and orbital infections. Pediatr Rev. 2004;25(9):312-20.

8 Chandler JR, Langenbrunner DJ, Stevens ER. The pathogenesis of orbital complications in acute sinusitis. Laryngoscope. 1970;80(9):1414-28.

9 American Academy of Pediatrics. Subcommittee on Management of S, Committee on Quality I. Clinical practice guideline: management of sinusitis. Pediatrics. 2001;108(3):798-808.

10 Lessner A, Stern GA. Preseptal and orbital cellulitis. Infect Dis Clin North Am. 1992;6(4):933-52.

11 Roscoe DL, Hoang L. Microbiologic investigations for head and neck infections. Infect Dis Clin North Am. 2007; 21(2):283-v.

12 Rudloe TF, Harper MB, Prabhu SP, Rahbar R, Vanderveen D, Kimia AA. Acute periorbital infections: who needs emergent imaging? Pediatrics. 2010;125(4):e719-26.

13 Ambati BK, Ambati J, Azar N, Stratton L, Schmidt EV. Periorbital and orbital cellulitis before and after the advent of Haemophilus influenzae type B vaccination. Ophthalmology. 2000;107(8):1450-3. 
Rossetto et al.: Hordeolum Complications

14 Hurley MC, Heran MK. Imaging studies for head and neck infections. Infect Dis Clin North Am. 2007;21(2): 305-vi. v-vi.

15 Mathew M. Munomycin in hordeolum externum. Indian Pract. 1966;19(10):689-90.

16 Lindsley K, Nichols JJ, Dickersin K. Interventions for acute internal hordeolum. Cochrane Database Syst Rev. 2013; 4, 9:CD007742.

17 Olson MD. The common stye. J Sch Health. 1991;61(2):95-7.

18 Fraunfelder FT, Roy FH. How to treat common external eye problems. Am Fam Physician. 1971;3(4):104-9.

19 Barza M, Baum J. Ocular infections. Med Clin North Am. 1983;67(1):131-52.

20 Einarsson OJ, Pers M. Streptococcal gangrene of the eyelids. Case reports. Scand J Plast Reconstr Surg. 1986; 20(3):331-5.

21 Placik OJ, Pensler JM, Kim JJ, Mets MB, Engel JM. Necrotizing periorbital cellulitis. Ann Plast Surg. 1993;31(4): 369-71.

22 Hill J, Alun-Jones T. Eyelid necrosis complicating acute maxillary sinusitis. J Laryngol Otol. 1989;103(4): 413-4.

23 Rosenthal WN, Gore HL, Insler MS. Periorbital necrotizing fasciitis. Ann Ophthalmol. 1987;19(11):426-7.

24 Raja V, Job R, Hubbard A, Moriarty B. Periorbital necrotising fasciitis: delay in diagnosis results in loss of lower eyelid. Int Ophthalmol. 2008;28(1):67-9.

25 Goh T, Goh LG, Ang CH, Wong CH. Early diagnosis of necrotizing fasciitis. Br J Surg. 2014;101(1):e119-25.

26 Lancerotto L, Tocco I, Salmaso R, Vindigni V, Bassetto F. Necrotizing fasciitis: classification, diagnosis, and management. J Trauma Acute Care Surg. 2012;72(3):560-6.

27 Lin JN, Chang LL, Lai CH, Lin HH, Chen YH. Group A streptococcal necrotizing fasciitis in the emergency department. J Emerg Med. 2013;45(5):781-8.

28 Wong CH, Wang YS. The diagnosis of necrotizing fasciitis. Curr Opin Infect Dis. 2005;18(2):101-6.

29 Steer AC, Lamagni T, Curtis N, Carapetis JR. Invasive group a streptococcal disease: epidemiology, pathogenesis and management. Drugs. 2012;72(9):1213-27.

30 Amrith S, Hosdurga Pai V, Ling WW. Periorbital necrotizing fasciitis: a review. Acta Ophthalmol. 2013;91(7): 596-603.

31 Lazzeri D, Lazzeri S, Figus M, Tascini C, Bocci G, Colizzi L, et al. Periorbital necrotising fasciitis. Br J Ophthalmol. 2010;94(12):1577-85.

32 Wang YS, Wong CH, Tay YK. Staging of necrotizing fasciitis based on the evolving cutaneous features. Int Dermatol. 2007;46(10):1036-41.

33 Deneubourg DL, Catherine Z, Lejuste P, Breton P. Periorbital necrotizing fasciitis induced by Streptococcus pyogenes: a case report and clarification. J Oral Maxillofac Surg. 2018;76(1):154-e5.

34 Henrich DE, Smith TL, Shockley WW. Fatal craniocervical necrotizing fasciitis in an immunocompetent patient: a case report and literature review. Head Neck. 1995;17(4):351-7.

35 Proia AD. Periocular necrotizing fasciitis in an infant. Surv Ophthalmol. 2018 Mar - Apr;63(2):251-6.

36 Lim VS, Amrith S. Necrotising fasciitis of the eyelid with toxic shock due to Pseudomonas aeruginosa. Singapore Med J. 2010;51(3):e51-3.

37 Koornneef L. Eyelid and orbital fascial attachments and their clinical significance. Eye (Lond). 1988;2 (Pt 2) (Pt 2):130-4.

38 Meyer DR, Linberg JV, WobigJL, McCormick SA. Anatomy of the orbital septum and associated eyelid connective tissues. Implications for ptosis surgery. Ophthal Plast Reconstr Surg. 1991;7(2):104-13.

39 Moscona R, Ullmann Y, Peled I. Necrotizing periorbital cellulitis following septorhinoplasty. Aesthetic Plast Surg. 1991;15(2):187-90.

40 Seal D, Leppard B, Widdowson J, McGill J, Tormey P. Necrotising fasciitis due to streptococcus pyogenes. Br Med J. 1980;280(6229):1419-20. 